\title{
INVESTIGACIÓN/RESEARCH
}

\section{LA BURBUJA AUDIOVISUAL DE LA TDT Y LA CRISIS FINANCIERA: UN CÓCTEL MOLOTOV PARA LA TV}

Elvira Calvo-Gutiérrez ${ }^{1}$ : Universidad Complutense de Madrid, España. ecalvogu@ccinf.ucm.es

\section{RESUMEN}

La llegada de la TDT prometía mejorar sustancialmente el panorama televisivo en España pero en realidad no ha sido así. Durante 2010 y 2011 hemos asistido a cambios sustanciales e importantísimos en los nuevos canales. Intereconomía TV se ha convertido en una televisión generalista; Tele 5 ha adquirido Cuatro; CNN+ pasó a ser Gran Hermano TV; Veo 7, de El Mundo, cesó temporalmente sus emisiones por falta de rentabilidad; y La 10, de Vocento, ha prescindido de sus informativos y de la producción propia. Los canales privados se ven obligados a fusionarse o a cerrar y los públicos atraviesan serias dificultades para sobrevivir. La burbuja audiovisual que ha traído la TDT y la crisis financiera forman un cóctel molotov para la televisión. La TDT está dejando mas víctimas por el camino que beneficios se esperaban. Ni diversificación, ni calidad de contenidos, ni servicio público. La Televisión es, cada vez más intrascendente.

PALABRAS CLAVE: TDT - Operadores privados - Televisiones autonómicas Mercado audiovisual - Telespectadores

\footnotetext{
1 Autor correspondiente:

Elvira Calvo Gutiérrez: Profesora en el Departamento de Periodismo II de la Facultad de Ciencias de la Información de la Universidad Complutense de Madrid. España

Correo: ecalvogu@ccinf.ucm.es
} 


\title{
THE AUDIOVISUAL BUBLLE OF DDT AND THE FINANCIAL CRISIS: A MOLOTOV COCKTAIL FOR TV
}

\begin{abstract}
The arrival of the DDTV was promising to improve substantially the television panorama in Spain but actually it has not been like that. During 2010 and 2011 we have been present at the substantial and most important changes in the new channels. Intereconomía TV has turned into a general television; Tele 5 has acquired Four; CNN+ happened to be Gran Hermano TV; Veo 7 (of El Mundo) stopped temporarily its emission for lack of profitability; and La10, of Vocento, has done without his informative ones and without the own production. The private channels meet obliged to fuse or to close and the public ones cross serious difficulties to survive. The audiovisual bubble that has brought the DDTV and the financial crisis they form a Molotov cocktail for the television. The DDTV is stopping mas victims for the way for that benefits were waiting. Neither diversification, nor quality of contents, nor public service. The television is, every time, more inconsequential.
\end{abstract}

KEY WORDS: DDTV - Privates operators - Regional televisions - Audio-visual market - Viewers

\section{INTRODUCCIÓN}

La llegada de la TDT prometía mejorar sustancialmente el panorama televiso en España. Con su implantación, fuimos pioneros en Europa pero la baja calidad de los contenidos ensucia el esfuerzo que realizamos con el apagón analógico. Durante 2010 y 2011 hemos asistido a cambios sustanciales e importantísimos en los nuevos canales. Intereconomía TV se convirtió en una televisión generalista; las 24 horas de información de CNN+ pasaron a ser 24 horas de Gran Hermano; Tele5 adquirió Cuatro; Veo 7, de El Mundo, apostó por los debates políticos nocturnos a base de talonario y meses después cesó temporalmente sus emisiones por falta de rentabilidad; La 10, de Vocento, ha prescindido de sus informativos y de la producción propia y emite series y películas.

A más oferta televisiva, más paro en la profesión periodística. Paradójico. Según el Observatorio de la Asociación de la Prensa de Madrid, en 2011, casi 3.000 periodistas han perdido su empleo en la capital: el cierre de Veo 7, el ERE de Prisa y los despidos de Marca TV han sido las principales causas pero no las únicas. También la prensa y la radio, y las productoras satélites, están en la cuerda floja.

La TDT está dejando mas víctimas por el camino que beneficios se esperaban. ¿Ha dejado la televisión de ser un servicio al ciudadano para convertirse en un negocio más? ¿Se han olvidado de la calidad? ¿Dónde queda su contribución a formar la 
identidad cultural de un país? Todo apunta a que la televisión es, cada vez, más intrascendente.$¿ \mathrm{O}$ es la audiencia?.

Ante este panorama, no hay que olvidar el papel de las televisiones públicas y su consideración actual. Amenazadas por problemas de rentabilidad, el sector de cadenas autonómicas se tambalea hasta el punto de que cada vez se habla con mas fuerza de privatización e, incluso, de desaparición. La economía, como dice Bustamante (1992, p. 32), es imprescindible hoy en día para entender el funcionamiento de la televisión, desde la producción de programas hasta las estrategias de programación y de marketing. La televisión ha ido engendrando formas muy diversas, públicas y privadas, analógicas y digitales, gratuitas o de pago, pero la lógica económica se impone en todas ellas como hegemónica. La transformación permanente de la televisión muestra así su cara onerosa y su corazón económico.

Gracias a la liberalización económica y al desarrollo tecnológico, la televisión ha adquirido gran protagonismo, y la mayoría de los grandes grupos de comunicación son empresas multimedia con fuerte presencia en el medio televisivo. Para tomar decisiones y desempeñar con acierto tareas profesionales en este ámbito es necesario comprender bien el funcionamiento del mercado y de sus compañías. (Medina Laveron, 2011). Caminamos hacia un nuevo modelo globalizado de televisión donde priman los intereses comerciales frente a los culturales. ¿Quién y cómo cubrirá el hasta ahora papel socializador de la televisión? ¿Puede ser Internet, una red donde todo es posible, no hay controladores y el consumo es individual?

\section{METODOLOGÍA}

El presente artículo parte de una necesidad epistemológica inicial sustentada, en primer lugar, sobre una exhaustiva analítica de fuentes para describir el status quo de partida del objeto de nuestro estudio $y$, posteriormente, en una segunda fase, unida indeleblemente a la anterior, pasaría a basarse en un análisis textual que incluye no sólo el estado de la cuestión hasta el momento, sino nuevos contenidos y aportaciones a la investigación, de manera que holísticamente se alcance una hermenéutica plena, tratando de eludir problemas interpretativos (deductivo-culturales) y de elidir los aspectos, que por consabidos, frenarían el avance del texto so pretexto de una hipertrofiada detención en los detalles confortantes que el acervo propio del lector avezado en temas comunicativos (lector ideal), se presupone, atesora.

El proceso inductivo-deductivo, basado tanto en estudios de fuentes como de casos, así como la proyección de nuevas ideas apalancadas en los criterios canónicos anteriores, se erige como el método adecuado para poder avanzar en los conocimientos en el área de la comunicación, entendida ésta no sólo como fin (objeto de estudio) sino también como medio (vehículo para transmitir otros saberes humanísticos propios de una publicación científica del área de Humanidades). 
Los textos ya existentes sobre la TDT han permitido a esta investigación avanzar en cuanto a la aportación de datos necesarios para establecer un análisis de contenidos en cuanto a formas de expresión (géneros) y contenidos (temática) de la nueva oferta televisiva en España desde la implantación de dicha tecnología.

\section{ANÁLISIS Y DISCUSIÓN}

\subsection{La situación crítica de los operadores de TDT privados...}

Un año y medio después del apagón analógico, en abril de 2010, que nos puso a la cabeza de Europa en la implantación de la TDT, el sector español se está convirtiendo en el farolillo rojo del continente. La crisis financiera ha traído consigo una importante disminución de la publicidad que está haciendo estragos en la burbuja audiovisual, en la que muchos canales surgieron de dudosos concursos públicos, mas con fines políticos que de servicio a la ciudadanía.

Después de Reino Unido, España es el segundo país europeo con mayor número de televisiones, mas de mil. La tarta publicitaria (que ha decaído en el primer semestre de 2011 mas de un 7\%), no da para todas, teniendo en cuenta que la mitad se la llevan Telecinco y Antena 3.

La facturación publicitaria cayó en el primer semestre del año (2011) un 5,9\%, según un informe de InfoAdex. Aunque para la televisión el resultado fue peor (descendió un $7,4 \%$ ), y para las cadenas autonómicas (TVE dejo de emitir anuncios el año pasado) el balance ha sido especialmente nefasto.

De los 1.214 millones de euros de inversión publicitaria que absorbió el medio televisivo, el grupo Telecinco acaparó 525 (43,3\%) y Antena 3 facturó 366 (30,1\%). Junto a estos dos colosos conviven emisoras con problemas de continuidad. Intereconomía, con una facturación en el primer semestre de 6 millones de euros (el $33 \%$ menos que en el mismo periodo del año anterior) ha iniciado una cuestación entre sus espectadores para sobrevivir. Los ingresos no llegan casi ni para pagar a Abertis, la distribuidora de la señal. El principal competidor de Intereconomía $(1,3 \%$ de audiencia), Veo 7, la televisión de Unidad Editorial (editora de El Mundo y Marca), ha despedido a la plantilla y ha llenado la parrilla de teletienda. Ahora espera llegar a un acuerdo con alguna multinacional (Fox y Discovery son las mejor situadas) para alquilar la frecuencia. Con el cambio, Veo 7 es prácticamente invisible. Casi tanto como $13 \mathrm{TV}$, una de las frecuencias que Unidad Editorial tiene arrendadas. Este canal ha sustituido a Popular TV, impulsado por la Conferencia Episcopal, con una audiencia residual: 0,5\% el pasado julio. En situación similar (0,6\%) está La 10, la televisión de Vocento. Cuotas demasiado exiguas para mantenerse en el aire.

El panorama no es mejor para los canales privados. Desolador, y desalentador, fue el cierre de CNN+ que cesó sus emisiones en diciembre de 2010. El canal fue vendido a Mediaset/Tele 5 que, durante unos meses, utilizó la frecuencia para Gran Hermano y actualmente emite Divinity dirigido a un público eminentemente femenino. 
Ese mismo año, 2010, Intereconomía TV se convirtió en una televisión generalista que, un año y medio después, y a pesar de haber recibido una importante inversión por parte de Mario Conde, nuevo socio, el canal se encuentra ahora solicitando dinero a sus telespectadores y con la vista puesta en el triunfo del Partido Popular en las elecciones del 20-N por si el gobierno que surja tiene a bien concederles alguna subvención. La facturación del primer semestre de 2011, de 6 millones de euros (el $33 \%$ menos que en el mismo periodo del año anterior), no le da ni para pagar a Abertis, la distribuidora de la señal. Además, desde que fuera resintonizada ha perdido audiencia.

Veo 7, el canal de El Mundo, despidió al que fuera su primer director, Melchor Miralles, por los bajos datos de audiencia. En su lugar puso a Ernesto Sáenz de Buruaga, un experto en contratos blindados que cobra una vez consigue arruinar el canal (lo hizo en TVE, en Antena 3 TV y en la Televisión de Murcia). En Veo 7 también: apostó por las tertulias políticas (ya las hacía en Telemadrid con Madrid Opina, 4 temporadas en prime time) y a golpe de talonario fichó a clásicos como Fermín Bocos, Luis Herrero y al propio Pedro J. Ramírez, para que, cada día de la semana, moderaran el debate con la habitual ronda de tertulianos (individuos que, con la crisis mediática parece que han dado por finalizadas sus respectivas carreras profesionales y ahora se dedican a ir de medio en medio de forma que uno ya se los encuentra hasta en la sopa dando vueltas y vueltas a las mismas ideas, lo que, al fin y a la postre, les asegura un sueldo importante). La gestión de Buruaga duró un embarazo. Pedro J le acusó de mala gestión y prescindió de él en marzo de 2011 lo que le permitió dedicarse en cuerpo y alma al matinal de la COPE que para eso le contrataron por 3 millones de euros hasta 2015. El resultado fue que Veo 7 se convirtió en Teletienda. Al finalizar el verano de 2011, y con unas elecciones generales de por medio, el canal vuelve a sus orígenes y apuesta por el todoterreno Carlos Cuesta quien desde el 12 de septiembre vuelve a las noches con un programa de análisis político. Será el único programa de producción propia del canal mientras se habla de un acuerdo con alguna multinacional (Fox y Discovery) para alquilar la frecuencia.

Con una audiencia del 0,6\%, La 10, de Vocento, dejó de emitir producción propia (la tertulia política de Curri Valenzuela y los informativos de Ángel Expósito) el 10 de junio de 2011. A inicios del otoño busca socios extranjeros (Fox, MTV, ...) para poder continuar.

La frecuencia de 13 TV pertenece a Unidad Editorial que la tiene arrendada a la Conferencia Episcopal en sustitución de Popular TV pero con la que alcanza al 0,5\% de la audiencia.

Otra TDT, Libertad Digital, de Federico Jiménez Losantos, que además está visible en las plataformas de pago como ONO e Imagenio, se planteó, en agosto de 2009, alquilar parte de su emisión. La crisis económica le obligó a reordenar sus prioridades que parece que pasan por Madrid y por Internet con una plantilla de diez personas. Tras lanzar una ampliación de capital por 1,2 millones de euros, redujo costes 
desmantelando las redacciones de Valencia (con varios canales locales en Sagunto, Alzira, Elche...) y Murcia. Las concesiones obligan a realizar producción propia y a incluir contenidos locales por lo que resultaban muy costosas. Liberta Digital TV se propuso un centro de producción de contenidos en Madrid para nutrir a las regionales que quedarían en manos de empresarios locales. Los estudios de televisión están siendo reutilizados por las redacciones de esRadio.

\section{2 Serias dificultades de los canales autonómicos}

Los canales públicos están en constante revisión. Desde que el gobierno de Zapatero consiguió que TVE prescindiera de la publicidad, los ajustes presupuestarios y de plantilla así como las polémicas no cesan. No hay forma de arreglar sus finanzas. Los mismos problemas, pero a escala regional, concurren en las televisiones de las CCAA cuyos parlamentos se están dejando la piel en su supervivencia hasta el punto de que muchos se preguntan ya si realmente son necesarias en tiempos de crisis. La privatización cuelga de sus cabezas como espadas de Damocles. Sin hablar de las municipales: Madrid fue de los primero grandes ayuntamientos en clausurar su televisión es.Madrid. Gallardón anunció su cierre a finales de mayo de 2010. Un año después, lo hizo la televisión de Mallorca y la de Oteniente, en Valencia. A finales de febrero cerró, también en Mallorca, Popular TV, propiedad de la COPE, del Obispado y de Barceló Hoteles.

Los partidos políticos, y hasta los ciudadanos, se plantean si son necesarias en el ámbito de la TDT con sobreabundancia de canales. El Partido Popular tiene clara su estrategia y ya anunciado que cuando llegue al poder cambiará la Ley General Audiovisual para privatizar las emisoras autonómicas.

Canal 9, en la Comunidad Valenciana, tiene una deuda de 1.300 millones de euros (solo en 2009 perdió 278 millones). Desde la llegada del Partido Popular en 1995, el agujero se ha multiplicado por 40. Su plantilla no deja de crecer (2.000 empleados, mas que Antena 3 y Tele 4 juntas) y su audiencia no ha dejado de caer. El presidente de la Generalitat, Alberto Fabra, no descarta un ERE para sanear y después vender.

Telemadrid apenas tiene un $5 \%$ de cuota de pantalla. Lleva tres años reduciendo plantilla. En 2007 contaba con 1.442 empleados y actualmente (octubre de 2011) tiene 1.156 (nueve veces mayor que la de Aragón que emplea a 130 personas porque, entre otras cosas, tiene externalizados buena parte de la producción y varios servicios).

La Televisión del Principado de Asturias (TPA) está tocada de muerte desde que el gobierno de Álvarez Cascos (Foro Asturias) decidiera cancelar la transferencia de 13,2 millones de euros asignada en el presupuesto de 2011. TPA ha recurrido a los tribunales y presentado un preconcurso de acreedores. Si los fondos no llegan pronto, se verá abocada al cierre inmediato.

Prejubilaciones, planes de ahorro, presupuestos a la baja, ajustes de plantilla9. El descenso de los ingresos publicitarios causado por la crisis y la caída de las audiencias 
generada por la irrupción de la TDT han colocado a buena parte de los trece canales dependientes de las comunidades autónomas entre la espada y la pared. El crecimiento del 'agujero' que acumulan -1.480 millones en el 2009- es tal que algunas autonomías se plantean su traspaso a manos privadas o incluso su cierre.

Aquellos primeros canales que vieron la luz hace ya casi tres décadas -ETB, el pionero, se creó en 1982 y TV3 en 1983- entre el respaldo e incluso el entusiasmo de una importante parte de la sociedad han devenido en auténticos agujeros negros donde prima la política y se tira el dinero público.

Los datos que se barajan no siempre coinciden. Según un informe de la consultora Deloitte encargado por las cadenas privadas, las autonómicas costaron en el 2009 a las comunidades 813 millones de euros en subvenciones, ingresaron 233 millones por publicidad y registraron unas pérdidas de 772 millones. La FORTA habla de unos ingresos publicitarios de 211 millones, de unas aportaciones públicas que suman 1.179 millones y de un desajuste entre ingresos y gastos que no llegaría a los 90.000 euros.

La diferencia entre las pérdidas calculadas por una y otra fuente (de 772 millones a 90.000 euros) podría servir de metáfora para ilustrar la distancia que separa a las privadas de las públicas. Las primeras, que están a punto de presentar un nuevo informe sobre las cuentas del 2010 de todas las televisiones, acusan a las autonómicas de competencia desleal por recurrir a la doble financiación (publicidad y ayudas públicas). Silvio González, consejero delegado de Antena 3, lo decía así de claro en unas jornadas celebradas por la UTECA: “Es objetivamente insostenible que empresas públicas compitan con empresas privadas ejerciendo exactamente la misma actividad que ellas, obteniendo sus ingresos en el mismo mercado publicitario y, además, recibiendo importantísimas ayudas públicas sin ninguna contrapartida real». Las autonómicas, por el contrario, defienden su tarea de dinamización del tejido audiovisual local y aseguran que aplican una política de contención que está en consonancia con la situación de crisis. Según el Secretario General de la FORTA, Enrique Laucirica, los gastos presupuestados para el 2011 son un $16 \%$ inferiores a los del 2008.

La política restrictiva que las autonómicas dicen haber adoptado no impide que algunos de los datos que han salido a la luz en los últimos tiempos las hayan puesto en una situación comprometida. Resulta desconcertante, por ejemplo, que Canal 9 tenga una plantilla de 1.800 trabajadores, más que Tele 5 y Antena 3 juntas. O que cada hogar español desembolse 126 euros por mantener las autonómicas mientras que paga 61 por sostener TVE (datos del 2009). El PP, que gobierna ahora en la mayor parte de las comunidades, ha anunciado su propósito de revisar la Ley General de la Comunicación Audiovisual para allanar el camino a la entrada de capital privado en las autonómicas. Tanto Esperanza Aguirre como María Dolores de Cospedal, presidentas de las comunidades de Madrid y Castilla-La Mancha, han expresado su voluntad de privatizar los canales de ambas autonomías en cuanto el cambio legal sea una realidad. 
El enfoque es claramente financiero. Las televisiones de servicio público tienen como principal objetivo un modelo de contenidos, mientras que las comerciales buscan sobre todo vender publicidad. Las autonómicas surgieron con un propósito muy definido que iba en la línea de promocionar contenidos en el idioma propio de aquellas autonomías que lo tenían para crear lazos de comunidad. Lo que hay que analizar es si ese modelo sigue siendo válido a día de hoy, o si conviene actualizarlo teniendo en cuenta la multiplicación del número de autonómicas o fenómenos estructurales como la fragmentación de las audiencias provocada por la TDT y el crecimiento de las televisiones conectadas.

Las televisiones autonómicas deberían seguir siendo necesarias como servicio público, por cercanía, y como instrumento cultural. Pero los números cantan. El alarmante 'agujero' en las cuentas de las comunidades -en el 2009 se hablaba de 1.480 millonescoloca en una situación cada vez más delicada a sus televisiones. El PP sugiere privatización porque, por lógica, ese dinero hará más bien si se dedica a sanidad o educación. En la calle, la opinión es clara. Como dice Alejandro Nieto en su blog financiero ‘El blog salmón’:

Todo muy bonito pero nadie privatiza las televisiones públicas. Y debería hacerse. Debería hacerse porque el único motivo para tener servicios y empresas públicos es para cumplir una labor social, con un reparto de los costes de una forma proporcionada a los ingresos. Las basuras deben recogerse, y no por tener poco dinero debe haber un mal servicio de recogida. Las calles deben estar asfaltadas. Debemos tener asistencia médica, no podemos dejar morir a la gente por no tener dinero. Y una larga lista. Pero en esta lista no me encaja la televisión pública. ¿Para qué necesitamos la televisión pública? ¿Qué función social cumple que no lo hagan las televisiones privadas? Pero si hay más función social en vídeos de aficionados de Youtube que en algunos de los programas que se emiten en las televisiones públicas. Tampoco es que la programación de las privadas es que sea una maravilla, pero por lo menos no las pagamos entre todos. Para lo único que sirven las televisiones públicas es para dar bombo al partido que está en el poder. Y las televisiones de los ayuntamientos más de lo mismo. Es un exponente más del derroche público en el que vivimos inmersos. Vivas donde vivas puedes ver varias televisiones públicas estatales, una o varias autonómicas y seguramente una del ayuntamiento. ¿Para qué? (Nieto, A., El blog salmón, 2011).

Las autonómicas se enfrentan a una etapa que va a conformar el futuro del modelo televisivo público español. En sus plantillas, que suman este año 7.172 trabajadores, según la FORTA, se respira una inquietud que se acentúa con los recortes salariales, los ERE e incluso los cierres.

La televisión autonómica se ahoga. Se acumulan recortes en los presupuestos, denuncias de mala gestión, sueldos abusivos y partidismo. La televisión pública española sigue sufriendo el huracán del debate político, pero nadie parece dispuesto a 
realizar una reflexión seria para definir un nuevo servicio público en la era digital, sostenible, de valor social y tapando de una vez el tubo de escape de la máquina de propaganda. La crisis de las autonómicas amenaza a un sector audiovisual muy dependiente del dinero público ${ }^{11}$. La mejor solución pasa por mantener las que tengan una audiencia superior a la media de la televisión de cobertura nacional, es decir, las que cumplan un fuerte servicio regional, y las que no sean rentables, podrían asociarse para compartir servicios, infraestructura, contenidos, etc.

Es la solución que aportaba la Unión de Televisiones Comerciales Asociadas (UTECA), presidida por José Miguel Contreras, el pasado mes de septiembre (2011): crear un canal público de cobertura nacional, sin publicidad, al que se puedan unir las televisiones autonómicas y que se nutriría de contenidos producidos por las mismas; una propuesta que se plantea para "rentabilizar mejor la inversión" de las mismas. Antes de poner sobre la mesa esta alternativa, calificad "de locos" por la FORTA, UTECA encargó un estudio a Deloitte para analizar los modelos de televisión regional de Europa. Se trataría de unir los modelos germano y británico. Sólo 9 de los 16 landers de Alemania tienen televisión propia (regional); los demás, comparten un único canal. Ésa es la idea para España: un único canal para todas las autonómicas en el que se podrían hacer desconexiones de 0 a 24 horas, con contenidos producidos por las CC.AA. que contribuyan al desarrollo económico y social de las regiones.

Sin embargo, la FORTA se opone totalmente a este planteamiento y mantiene que la financiación sea mixta (subvenciones y publicidad). Su postura se basa en que la política audiovisual del país la hacen las fuerzas parlamentarias no la UTECA ni otra asociación privada. El Partido Popular aboga por cambiar la Ley del Tercer Canal (abolida hace año y medio, cuando se aprobó la Ley General de la Comunicación Audiovisual) para que se puedan privatizar (de forma "total o parcial") las autonómicas. Entre los presidentes regionales hay división. Esperanza Aguirre (Madrid) y María Dolores de Cospedal (Castilla-La Mancha) se han decantado por privatizar los entes. La Comunidad Valenciana, sin embargo, aboga por un sistema público y CiU, en Cataluña, respalda que TV3 conserve su estatus.

\section{CONCLUSIONES}

Las promesas que anunciaba la TDT no se han visto cumplidas. No en España. La neotelevisión (interactiva y de más calidad) se ha quedado en un modelo televisivo que tan sólo se centra en la audiencia y los beneficios, tal como vaticinaba José Ángel Cortés en 1999 (Cortés, 1999, p. 83). A pesar de aumentar el número de canales, la diversidad brilla por su ausencia y la calidad de la programación deja mucho que desear. Y los telespectadores empiezan a aburrirse. Numerosas encuestas revelan que la gente joven apenas ve televisión y, si lo hace, es a través de Internet que les permite elegir el horario de emisión y además evitar la publicidad. La búsqueda desesperada de audiencias mediante la frivolización y la banalización, la avaricia por captar publicidad hasta el hartazgo y la falta de racionalización a la hora de programar están matando al actual modelo de televisión. Convertido en un negocio, el medio distrae, engaña, abusa y distorsiona la realidad. 
Una pena porque esa misma televisión podría haber servido para los objetivos para los que se creó: formar, informar y entretener en porcentajes lógicos. Los recursos audiovisuales podrían haber servido para educar a parte de la sociedad, para seguir en directo el funcionamiento de nuestras instituciones y la vida política. La televisión se creó para explicarnos el mundo y, sin embargo, se ha convertido en un campo de batalla donde lo único que se puede aprender es caótico.

El número de canales crece, pero en casi todos los casos como segundas y terceras opciones de la cadena principal: TVE (La 1, La 2, Clan, Teledeporte, HD); Antena 3 (HD, Neox y Nova); Tele5 (HD, Cuatro, FDF, Divinity, La 7, Boing); La Sexta (HD, La Secta 2 y 3). No obstante, alguna apuestas han cuajado en poco tiempo. La más evidente es la de los canales infantiles. Los niños han desaparecido de las cadenas tradicionales (como el deporte de La 2). Todo parece haber encontrado su lugar, en busca de una ordenación temática. Clan, de Televisión Española, es quizás el canal con más éxito de toda la parrilla de la TDT. Y parece que el éxito está asegurado para el futuro. El público infantil otorga también la primacía a Disney Channel, uno de los productos estrella de la casa que apostó por emitir en abierto, fuera de la plataforma digital de pago. Y este éxito explica también que Telecinco, dentro de su familia de canales (que acaban de crecer) haya apostado por Boing, muy valorada también por los más jóvenes. Exceptuando los contenidos infantiles y deportivos, no resulta fácil contenidos alternativos.

Los espectadores se quejan de que muchos sirven, sobre todo, para reiterar contenidos que ya han sido emitidos, es decir, para practicar la redifusión. Y por este motivo, los hábitos cambian: ya no hay pelea por el mando a distancia puesto que el consumo de la televisión ha pasado a ser individual, de ahí que las empresas audiovisuales luchen ahora por posicionarse en la televisión a través del móvil. En este ambiente de confusión, de nuevas ideas, de transición y de adaptación, las parrillas no dejan de redefinirse una y otra vez. Todos están convencidos de que la llegada de la TDT, con su multiplicación de canales, no ha mejorado el panorama audiovisual español. Sólo TVE ha apostado por la televisión de servicio público y sigue protagonizando las mayores cuotas de pantalla.

Lamentables, por la pobreza de ideas y opiniones que supone son las fusiones, la anunciada entre Antena 3 y La Sexta o la que ya es una realidad, el desembarco de Tele5 en Cuatro y en Digital Plus y el cierre de CNN+. El nuevo grupo se convierte en el mayor operador de televisión de España, con ocho canales de TDT y un 25,2\% conjunto de la audiencia, cerca del umbral legal del 27\%. Como en las cajas de ahorro, se impone la fusión de canales para ahorrar costes. Respecto a la desaparición de $\mathrm{CNN}+$, tan tristemente recibida por el sector periodístico y por la sociedad en general al pasar de la realidad mundial a la realidad de una casa en Guadalix de la Sierra, se ha visto con absoluta perplejidad y como una metáfora de estos tiempos duros para la comunicación. Los canales todo noticias no son rentables pero sí necesarios. 
Seguramente, en los próximos meses asistiremos a pruebas y a estrategias de diferente índole. Lo importante es que la calidad, si la hay, no se pierda. Nadie sabe, sin embargo, cómo evolucionarán los acontecimientos. Mientras los canales principales se reinventan, a veces al calor del fútbol o a través de la Fórmula 1 (cuyos derechos acaba de adquirir Tele 5) o el humor (como es el caso de la Sexta), los canales secundarios intentan alcanzar su propia personalidad. Nada difícil para canales como Clan, el resto de infantiles o los deportivos. 10 o Veo 7, al igual que Intereconomía, parecen haber encontrado un nicho que pasa, sobre todo, por el debate político y el debate deportivo. Pero los jóvenes se sienten más cerca de Neox, Nova o Nitro. Muchos de estos canales empiezan a perfilarse como las auténticas alternativas para el futuro. Pero ello dependerá de los contenidos. Dependerá de que consigan un carácter propio, un tanto diferenciado de sus canales principales. Neox, en la mayoría de las encuestas, aparece como uno de los canales secundarios más valorados. Algunas series alternativas y ciertos programas considerados demasiado avanzados están encontrado su lugar ahí. Algunos expertos creen que terminarán siendo más atractivos que las cadenas de las que dependen.

La evolución de las formas de consumo audiovisual tiene relación con el desarrollo económico, sociológico y tecnológico (Álvarez Monzoncillo, 1997, p. 64). Los españoles abonados a televisiones de pago aumentaron un $7 \%$ de media anual entre los años 2004 y 2010, aunque los ingresos cayeron un 2\%. Desde el apagón analógico, en 2010, es de suponer que los abonados disminuirán. Y habrá que estar atentos al desarrollo de la TDT de pago y saber cómo se va a acostumbrar la audiencia a pagar por algo que hasta ahora ha tenido gratis. El mismo error que cometió la prensa online.

Los canales privados se ven obligados a fusionarse o a cerrar y los públicos atraviesan su época más dolorosa. Teóricamente, la TDT aportaba una mayor democracia al sistema audiovisual. En la práctica, ha creado un modelo inviable y poco sostenible, una burbuja audiovisual que unida a la crisis financiera está haciendo estragos en el panorama audiovisual español. Sólo cabe concluir diciendo que la TDT está dejando mas víctimas por el camino que beneficios se esperaban y que la televisión se ha mercantilizado. ¿Hacia dónde va? El futuro de la televisión pasa por reinventar el modelo de canal público y por la diferenciación a través de contenidos de calidad, personalizados y de recepción flexible para los consumidores, ya que solamente de esta forma los operadores podrán hacer de la televisión de pago una de las claves en la reconversión del sector audiovisual. Habrá que verlo.

\section{REFERENCIAS}

Álvarez-Monzoncillo, J. M. (1997). Imágenes de pago. Madrid: Fragua.

Bustamante, E. (1999). La televisión económica: financiación, estrategias y mercados. Barcelona: Gedisa.

Cortés, J. A. (1999). La estrategia de la seducción. La programación en la neotelevisión. Pamplona: Eunsa. 
Infoadex (2011). Consultado el 09 de Diciembre del 2011 Disponible en: www.infoadex.es/

Medina Laveron, M. (2011). Estructura y gestión de empresas audiovisuales (2 ${ }^{a}$ edic), Pamplona: Eunsa.

Nieto, A. (2011). El blog salmón. Consultado el 29 de Agosto del 2011 Disponible en: http://periodistas21.blogspohttp://www.elblogsalmon.com/entorno/hay-queprivatizar-las-televisiones-publicast.com/2011/10/fin-del-sueno-audiovisualautonomico.html.

Nieto, A. (2011). El blog salmón. Consultado el 2 de Septiembre del 2011 Disponible en: $\underline{w w w}$.elblogsalmon.com/entorno/hay-que-privatizar-las-televisiones-publicas.

\section{Elvira Calvo Gutiérrez}

Profesora del Departamento Periodismo II de la Facultad de CC de la Información (UCM). Doctora en Periodismo por la UCM y Máster en Comunicación Empresarial e Institucional. Profesora invitada por el Institut für Kommunikations de la Universidad Otto Friedrich de Bamberg (Alemania) y por la Faculdade de Ciencias da Comunicação e da Cultura, Artes e Tecnologias da Informação de la Universidade Lusófona de Oporto (Portugal). Autora del libro La información económica en TV (Madrid, 2011). Profesionalmente cuenta con 25 años de experiencia, destacando sus trabajos en Telemadrid, Localia, Cadena SER y El Diario Montañés; en Red.es, Eurocofín, CEOE y Universidad Internacional Menéndez Pelayo. 